\title{
Diel and seasonal activity pattern of alien sika deer with sympatric mammalian species from Muljangori-oreum wetland of Hallasan National Park, South Korea
}

\author{
Maniram Banjade ${ }^{1}$, Sang-Hyun Han ${ }^{2}$, Young-Hun Jeong ${ }^{1}$ and Hong-Shik Oh ${ }^{3 *}$
}

\begin{abstract}
Background: Sika deer, Cervus nippon, were originally introduced to South Korea from Japan and Taiwan for commercial farming purposes. Unfortunately, they were released into the wild during religious events and have since begun to impact the native ecosystem and species endemic to South Korea. The study of activity patterns can improve our understanding of the environmental impact of non-native species and their association with sympatric species. Using camera traps, we studied the diel and seasonal activity patterns of non-native sika deer and quantified the temporal overlap with sympatric mammalian species in the Muljangori-oreum wetlands of Hallasan National Park, South Korea.
\end{abstract}

Results: A total of 970 trap events were recorded for five mammalian species from nine locations during the camera-trap survey. Siberian roe deer (Capreolus pygargus tianschanicus) had the highest number of recorded events (72.0\%), followed by sika deer (Cervus nippon) (16.2\%), wild boar (Sus scrofa) (5.0\%), Asian badger (Meles leucurus) (4.5\%), and the Jeju weasel (Mustela sibirica quelpartis) (2.0\%). Sika deer had bimodal activity patterns throughout the year, with peaks throughout the spring-autumn twilight, and day and night time throughout the winter. Relating the daily activity of sika deer with other mammalian species, roe deer expressed the highest degree of overlap $\left(\Delta_{4}=0.80\right)$ while the Asian badger demonstrated the lowest overlap $\left(\Delta_{4}=0.37\right)$.

Conclusions: Our data show that sika deer are a crepuscular species with seasonal variations in daily activity patterns. Additionally, we identified the temporal differences in activity peaks between different mammals in the Muljangori-oreum wetlands and found higher degree of overlap between sika deer and roe deer during twilight hours.

Keywords: Camera traps, Diel activity, Management, Sympatric species, Sika deer

\footnotetext{
* Correspondence: sciedu@jejunu.ac.kr

${ }^{3}$ Interdisciplinary Graduate Programme in Advance Convergence Technology

and Science, Faculty of Science Education, Jeju National University, Jeju

63243, South Korea

Full list of author information is available at the end of the article
}

C The Author(s). 2021 Open Access This article is licensed under a Creative Commons Attribution 4.0 International License, which permits use, sharing, adaptation, distribution and reproduction in any medium or format, as long as you give appropriate credit to the original author(s) and the source, provide a link to the Creative Commons licence, and indicate if changes were made. The images or other third party material in this article are included in the article's Creative Commons licence, unless indicated otherwise in a credit line to the material. If material is not included in the article's Creative Commons licence and your intended use is not permitted by statutory regulation or exceeds the permitted use, you will need to obtain permission directly from the copyright holder. To view a copy of this licence, visit http://creativecommons.org/licenses/by/4.0/ 


\section{Background}

The sika deer Cervus nippon (Artiodactyla: Cervidae) is an ungulate species non-native to South Korea. It was introduced from Japan and Taiwan for commercial farming, particularly for the purpose of antler production (Koh et al. 2010; Jin 2013). Between 1987 and 2002, numerous sika deer were released into the wild during various religious events. The invasive deer have since been identified in Songnisan National Park, South Korea (Kaji et al. 2010). Sika deer that were farmed in Jeju Island were also illegally released in Mt. Hallasan National Park; populations of sika deer have since been found distributed across various isolated patches of the park (Jo et al. 2018).

Despite the positive contributions of these improperly introduced ungulates (Garcia-Llorente et al. 2008), they have had significant negative impact on the ecosystem and native species (Carpio et al. 2016). In order to estimate the potential impact and establish guidelines for sustainable management, it is important to consider how alien species are adapted to suit their non-native environments. The study of activity patterns and the temporal overlaps between invasive and native species can be used to describe patterns of coexistence (Centore et al. 2018) and provide valuable data for managing the introduced species (Prpic et al. 2020). If population control measures are warranted, this knowledge allows wildlife managers to target specific times for the implementation of management actions, greatly improving efficiency. In general, wild ungulates exhibit a bimodal activity pattern that peaks at dawn and dusk (Stache et al. 2013; Ensing et al. 2014); the sika deer of Jeju Island likely follow a similar pattern. Understanding the activity patterns of non-native species is also important for identifying the potential interspecific interactions that exist when multiple species coexist in same habitat. Knowledge of these interspecific interactions is vital as they represent a leading cause of biodiversity loss (Spear and Chown 2009). Moreover, in an island ecosystem, both habitat and native species are more likely to be affected by the invasion of alien species.

In previous studies on the effect of invasive species on native plants and animals in South Korea (Oh et al. 2017; Adhikari et al. 2019), invasive species were found to adversely affect agriculture, horticulture, and wild ecosystems. However, the ecological impacts of sika deer on Jeju Island have not yet been detailed, though sika deer have been reported to negatively impact the urban forest ecosystem in mainland South Korea (Jin 2013). Furthermore, sika deer are likely to compete with sympatric ungulates, as has been reported in Europe and New Zealand (Fraser 1996; Bartos 2009; Biedrzycka et al. 2012). Numerous problems have been identified with the introduction of non-native deer in Britain (Putman
1996; Cooke and Farrell 2001), America (Cote 2005; Russell et al. 2017), and Italy (Bertolino et al. 2009; Feretti 2011).

Despite several studies in their native ranges in Taiwan and Japan (Ikeda et al. 2015; Liang et al. 2020), activity pattern data on non-native range are scarce in South Korea. This study aims to provide invaluable data for understanding the influence of alien ungulates on native species on Jeju Island. It also seeks to improve our understanding of the ecology and behaviour of sika deer, which is important information for species management and environmental protection. In this study, we investigate the diel and seasonal activity patterns of sika deer as well as the overlap of activity times with sympatric species in the Muljangori-oreum wetlands of Jeju Island using camera traps.

\section{Methods}

Study area

Muljangori-oreum (E126 31', N33 22', alt. $936 \mathrm{~m}$ ) is a volcanic mountain on Jeju Island containing a freshwater crater lake at the top (Fig. 1). This site was registered as Ramsar Wetland in 2008 and designated as a protected wetland area in 2009 (Kim et al. 2012). Muljangorioreum has a gently steep terrain and is home to various types of vegetation. The lowland area is largely covered with pasture and agricultural land, whereas the upland contains forbs and graminoids along with patches of deciduous and evergreen forest. Diverse plant species including the Japanese peony (Paeonia obovate), Geumsaeunan (Calanthe sieboldii), Bochunhwa (Cymbidium goeringii), Jeju Island's indigenous Korean wild ginger (Asarum maculatum), and Korean liverleaf (Hepatica insularis) grow in the wetland areas (Lee 2008). Moreover, there is significant faunal diversity including the Siberian roe deer (Capreolus pygargus tianschanicus), wild boar (Sus scrofa), Asian badger (Meles leucurus), and the Jeju weasel (Mustela sibilica quelpartis), as well as multiple endangered species such as the fairy pitta (Pitta nympha), peregrine falcon (Falco peregrinus), and the black paradise flycatcher (Terpsiphone corvina) (MoE 2011). Also worth noting, there are no large predatory animals endemic to these habitats.

\section{Camera trap survey}

To investigate the activity patterns of sika deer along with sympatric mammalian species, camera trapping (Bushwhacker, ROBOT D30, Shenzhen, China) was conducted between Oct 2018 and Sept 2019. In order to cover all habitat types and landscape structures, the study area was divided into a $1 \mathrm{~km}^{2}$ grid system. Due to limited camera availability $(n=9)$, only nine grid areas were sampled. In each grid, the locations for each camera were selected by identifying and following deer tracks (Fig. 1). Cameras were 


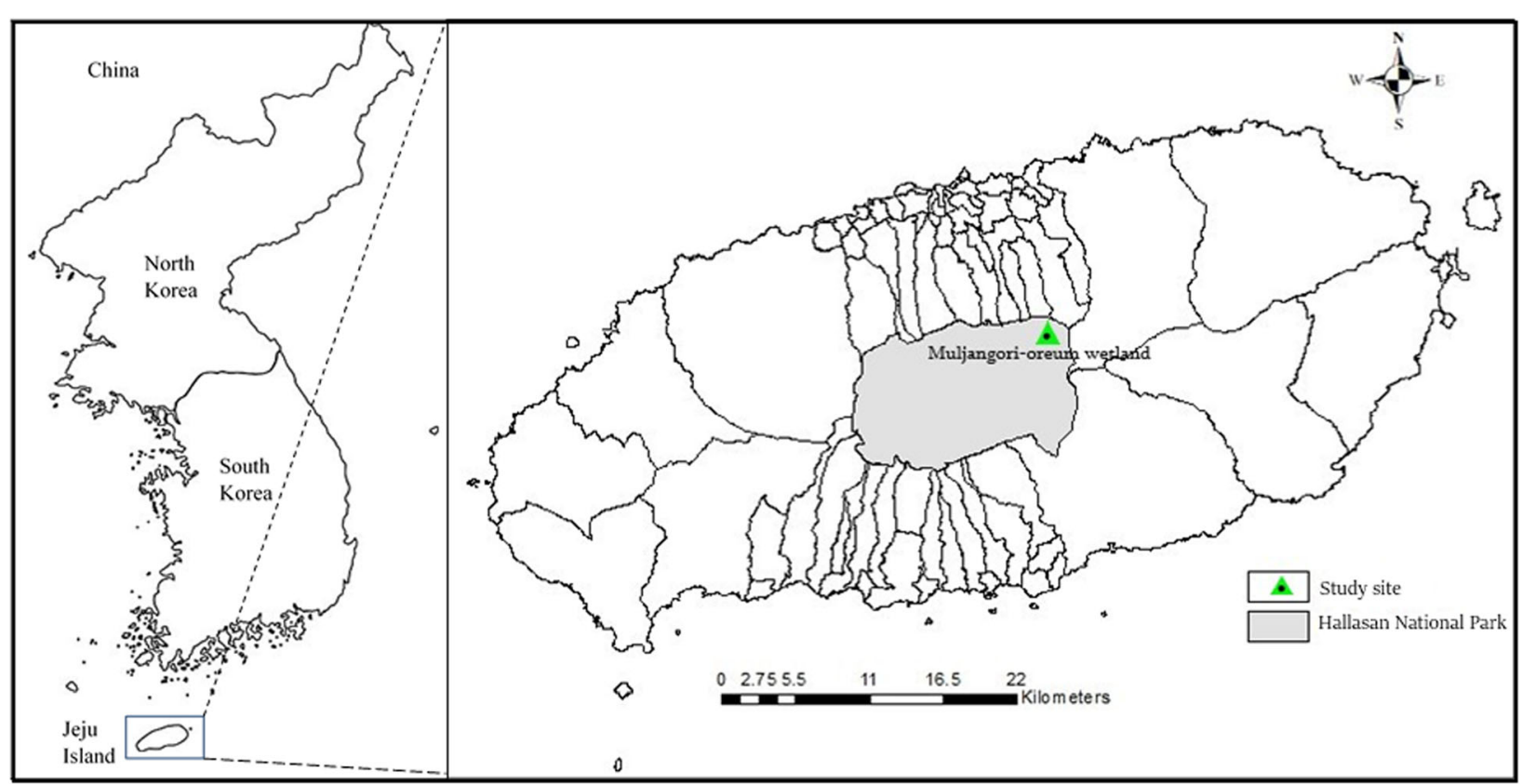

Fig. 1 Map showing the study area

strapped to trees $1 \mathrm{~m}$ above the ground and directed parallel to the deer trails. To record accurate activity patterns, all cameras were operational $24 \mathrm{~h}$ a day and programmed to take consecutive images and videos when triggered. In order to reduce potential bias caused by multiple records of the same individual at a camera station, photographs that were recorded within $30 \mathrm{~min}$ of previous photographs of the same species at same camera station were not used (O’Brien et al. 2003; Linkie and Ridout 2011). Camera captures of multiple individuals of social species were considered single events (Palmer et al. 2018). Data from the camera traps were collected monthly by exchanging SD- cards, and if necessary at the time, batteries were replaced. HOBO RX3000- Remote monitoring and weather stations (Bourne, USA) were set and identified the mean monthly fluctuations in temperature (Fig. 2). We divide the year into four seasons: spring (March-May), summer (June-August), autumn (September-November), and winter (DecemberFebruary). By analysing the images from camera traps, we estimated the activity patterns for each season.

\section{Data analysis}

We used kernel density estimation, a non-parametric technique for calculating the probability density function

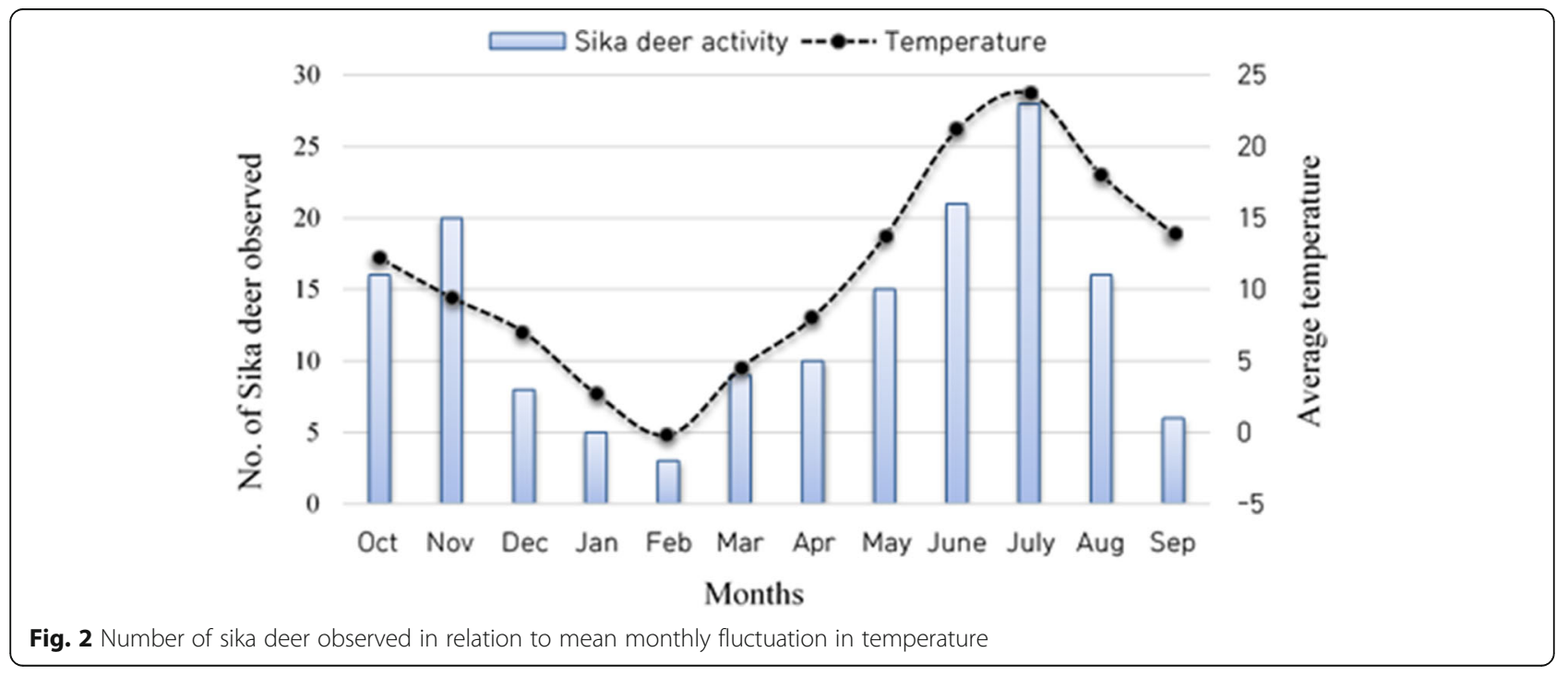


of random variables (Worton 1989), as described by Ridout and Linkie (2009) and Linkie and Ridout (2011) to estimate the seasonal and diel activity patterns of sika deer along with sympatric mammalian species. To measure difference in the behaviour patterns of sika deer and other observed species, we calculated the coefficient of overlapping $(\Delta)$, which ranges from 0 (non-overlap) to 1 (complete overlap) (Ridout and Linkie 2009). The coefficient is defined as the area under the curve that is formed by taking the minimum of the two density functions at each time point (Linkie and Ridout 2011). We used Dhat 1 for small sample sizes ( $<75$ records) and Dhat 4 for sample sizes greater than 75 records among the various density estimators (Meredith and Ridout 2018). Dhat $<0.50$ was interpreted as weak overlap, > 0.50 and $<0.60$ as moderate overlap, and $>0.60$ as high overlap (Massara et al. 2018). A precision of estimator of overlap was estimated by $95 \%$ confidence interval using bootstrap with 10,000 resamples (Foster et al. 2013; Meredith and Ridout 2018). We used the 'activity' R package (Rowcliffe et al. 2014) to statistically test the probability that two sets of observations came from the same distribution. We set the number of bootstrap iterations to 10,000 .

At each photograph, all cameras record the time, date, and temperature. The photographs were then processed using the Timelapse2 Image analyser (Greenberg 2019), which automatically extracts information from all images such as date and time. We classified diurnal (activity during day), nocturnal (activity during night), and crepuscular (activity during twilight) patterns; the classification was defined as cathemeral when no differences were observed among the three time periods (Bennie et al. 2014; Ikeda et al. 2016). We used one-way ANOVA to compare daily photographic frequency among the three time periods. Prior to ANOVA, Shapiro-Wilk and Cochran's $\mathrm{C}$ tests were used to check for normality and homogeneity of variance (Doncaster and Davey 2007). All these procedures were implemented in $\mathrm{R}$ software ( $\mathrm{R}$ Development Core Team, 2015) with the 'camtrapR' (Niedballa et al. 2016), 'overlap' (Meredith and Ridout 2018), and 'circular'(Lund et al. 2017) packages. The coefficient of overlap was calculated using 1.0 as the smoothing parameter.

Using the Moonrise 3.5 software package (Sidell 2002), we calculated the exact time of sunset and sunrise. All calculations were performed using Statistica 8.0 software (Statsoft, Inc.) and all mapping was performed using ArcMap 10.7 (Esri, Inc.)

\section{Results}

From a total of 2,942 trap nights, a total of 970 traps events were analysed from the nine trap locations. The trap events for sika deer (16.2\%) were second to those of roe deer $(72.0 \%)$. A much smaller number of trap events included wild boar (5.0\%), badger (4.5\%), and weasel (2.0\%) (Table 1).

\section{Activity pattern of sika deer}

Each photo recorded time was divided into three time periods: day (activity predominantly between $1 \mathrm{~h}$ after sunrise and $1 \mathrm{~h}$ before the sunset), night (activity predominantly between $1 \mathrm{~h}$ after sunset and $1 \mathrm{~h}$ before sunrise), and twilight (activity peaks $1 \mathrm{~h}$ before and after sunrise and sunset respectively). We found no significant difference in trap events among the three time periods between spring and autumn, but a significant difference was observed between winter and other three seasons $(F$ $=5.06$, d.f. $=2, P<0.05)$ (Table 2). Despite winter having the lowest number of sika deer trap events $(n=16$ events), the activity curve peaks moved more towards day and night hours as can be seen in Fig. 3 .

The daily activity pattern of sika deer exhibited a bimodal pattern. Most notably, activity curve peaks were changed from sunrise and sunset as they were between spring and autumn, to day and night in winter (Fig. 3). With the exception of winter, the mean number of sika deer trap events during twilight hours was significantly higher than that during day and night hours $(F=3.24$, d.f. $=3, P<0.05)($ Table 2$)$.

\section{Temporal activity overlap of sika deer with sympatric species}

With consideration to the activity overlap with other mammalian species, the activity of sika deer clearly overlapped with that of roe deer more than any other $\left(\Delta_{4}=\right.$ 0.80 ; $\mathrm{CI}=0.75-0.88$ ) (Table 3; Fig. 4). The activity patterns of both species overlapped throughout the day and night, with two distinct peaks of activity in the twilight hours.

The wild boar and sika deer had a low coefficient of activity overlap $\left(\Delta_{4}=0.54 ; \mathrm{CI}=0.50-0.70\right)$ compared to that with roe deer $\left(\Delta_{4}=0.74 ; \mathrm{CI}=0.66-0.86\right)$ (Table 3; Fig. 4). Wild boar showed cathemeral activity that peaked at noon and around midnight.

The badger was the only species that showed predominantly nocturnal behaviour (Fig. 4). The coefficient of activity overlap between badger and sika was lower $\left(\Delta_{4}\right.$

Table 1 Camera trap events of five species from nine locations

\begin{tabular}{llll}
\hline Species & Trap events (TE) & No. of pictures & \% of pictures \\
\hline Sika deer & 158 & 2014 & 25.2 \\
Siberian roe deer & 699 & 3708 & 46.4 \\
Wild boar & 49 & 1278 & 15.9 \\
Asian badger & 44 & 888 & 11.1 \\
Jeju weasel & 20 & 102 & 1.2 \\
Total & 970 & 7990 & 100 \\
\hline
\end{tabular}


Table 2 Seasonal pattern of diel activity in sika deer

\begin{tabular}{lllll}
\hline & \multicolumn{4}{l}{ Trap events \pm S.E } \\
\cline { 2 - 5 } Seasons & Twilight & Day & Night & $P$-value \\
\hline Spring & $3.50 \pm 1.38$ & $1.1 \pm 0.47$ & $1.0 \pm 0.36$ & 0.10 \\
Summer & $5.66 \pm 1.35$ & $2.5 \pm 0.67$ & $2.6 \pm 0.55$ & 0.05 \\
Autumn & $4.36 \pm 1.18$ & $1.5 \pm 0.61$ & $1.0 \pm 0.47$ & 0.71 \\
Winter & $0.66 \pm 0.66$ & $0.6 \pm 0.33$ & $1.8 \pm 0.54$ & $\mathbf{0 . 0 2}$ \\
P-value & $\mathbf{0 . 0 4}$ & 0.13 & 0.59 & \\
\hline
\end{tabular}

Values indicate the average trap events and SE. Difference in frequencies among three time periods was tested by one-way ANOVA
$=0.37 ; \mathrm{CI}=0.35-0.58)$ than that between weasel and sika deer $\left(\Delta_{4}=0.58 ; \mathrm{CI}=0.43-0.76\right)$ (Table 3; Fig. 4). The weasel had the greatest number of registrations in the daytime among all the studied species. Activity began from early morning with peaks towards mid-day, abruptly ceased at night.

\section{Discussion}

Herein, we have described the diel and seasonal activity patterns of alien sika deer as well as multiple sympatric species in the Muljangori-oreum wetlands of Jeju Island based on a camera trap survey. The data show that sika

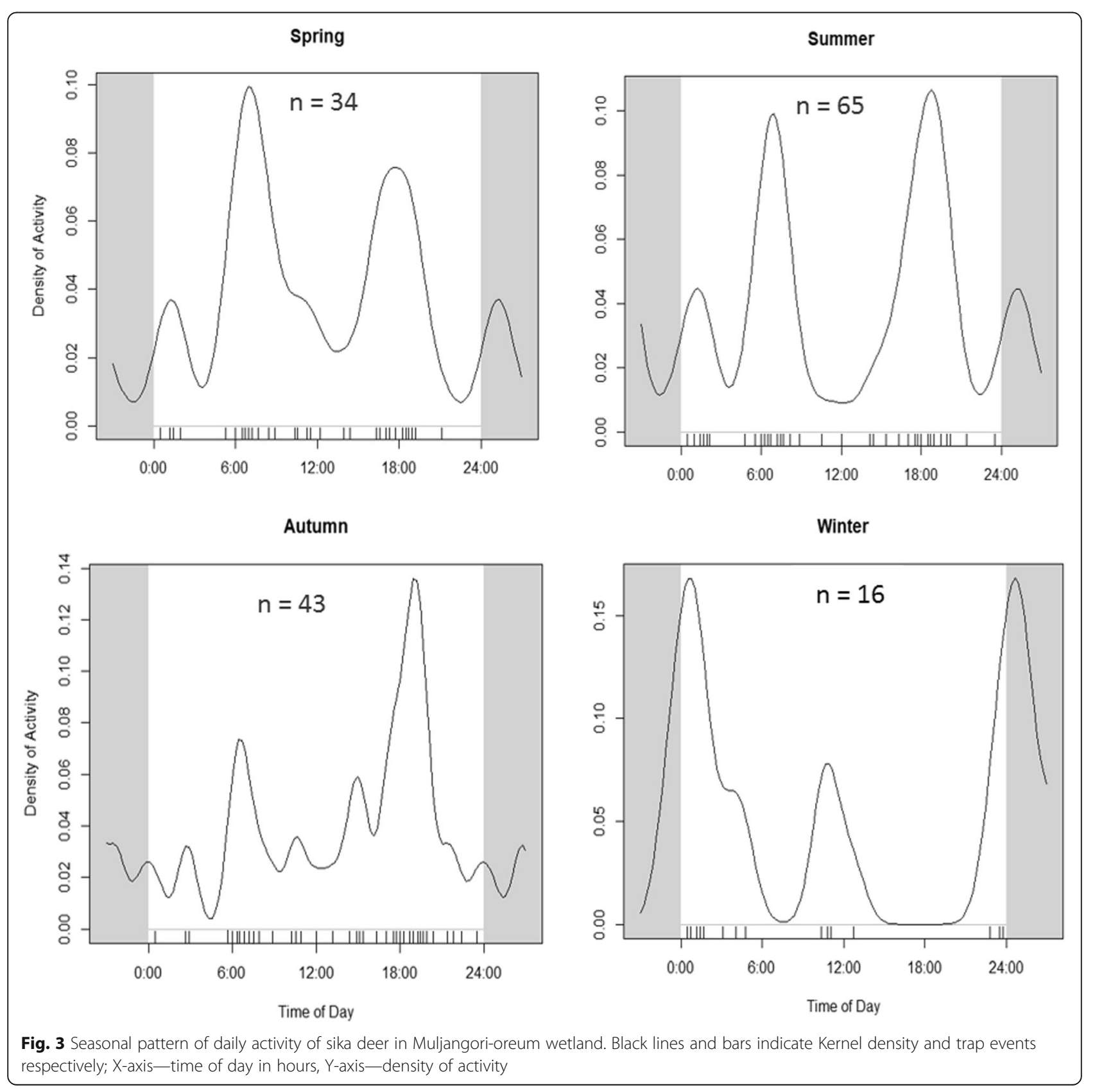


Table 3 Coefficient of daily activity overlapping (Dhat4) and their Cl for camera-trapped species

\begin{tabular}{ll}
\hline Sika deer & \\
$0.80(0.75-0.88)$ & Siberian roe deer \\
$0.54(0.50-0.75)$ & $0.74(0.66-0.86)$ \\
$0.37(0.35-0.58)$ & $0.54(0.48-0.68)$ \\
$0.58(0.43-0.76)$ & $0.59(0.45-0.74)$ \\
\hline
\end{tabular}

deer were active throughout the day, but had peaks of activity at twilight and troughs in the middle of the day and at night.

In the analysis of daily activity, sika deer mostly showed a bimodal activity pattern with the most activity during twilight hours. Studies from Japan (Borkowski 2001; Ikeda et al. 2016; Ikeda et al. 2019) have also

\section{Wild boar}

$0.70(0.55-0.83) \quad$ Asian badger

$0.44(0.29-0.63) \quad 0.15(0.09-0.37)$

Jeju weasel

reported that sika deer primarily show a crepuscular activity pattern. Similar bimodal patterns have been identified in many other ungulates including roe deer (Capreolus capreolus) (Pagon et al. 2013), white-tailed deer (Odocoileus virginianus) (Paul and Mccullough 1990), and elk (Cervus canadensis) (Green and Bear 1990). Frequent alternations between activity and rest

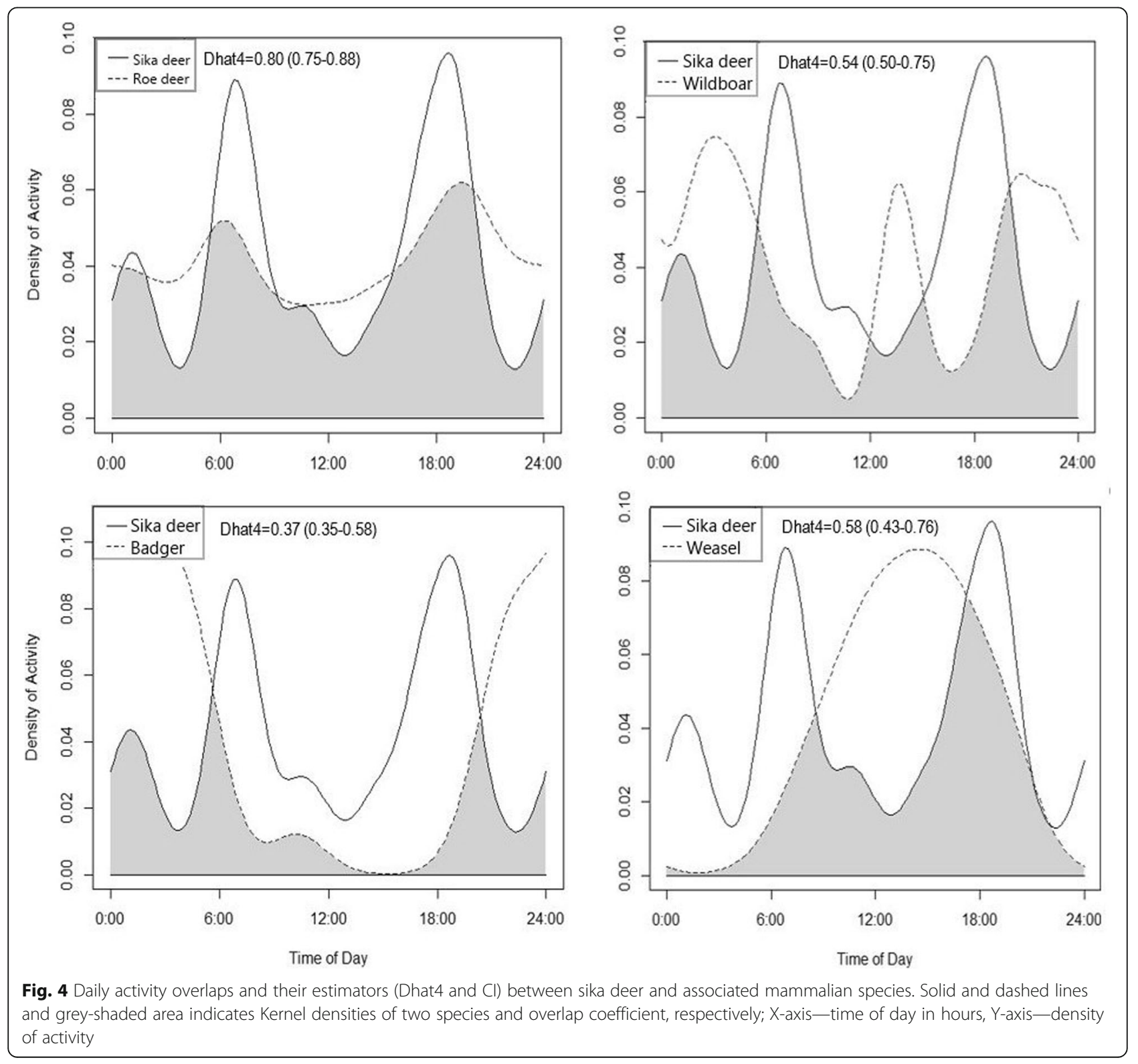


over the day/night cycle are indicative of a feeding and ruminating process, the timing of which ultimately depends upon the physiological and morphological constraints imposed by the digestive tract (Turner 1979; Berger et al. 2002).

Differences in the daily activity patterns of ungulates also arise based on climatic conditions (Pęksa and Ciach 2018). In warmer months, morning activity peaks earlier and evening activity later due to the typically low heat tolerance of most large mammals. As temperature and solar radiation rise during summer, the daytime activity of ungulates usually declines (Bourgoin et al. 2011; Brivio et al. 2016). The activity of sika deer was near absent during the harsh Korean winters, known for their low temperatures and high snowfall, which may have caused a seasonal migration toward lowland areas with less snow and easily available grazing lands. The migration to lower altitudes during winter has also been reported in the native roe deer of Jeju Island (Adhikari et al. 2016) as well as in the sika deer of Hokkaido Island (Igota et al. 2004). In addition, during winter, activity peaks shifted towards day and night (i.e. cathemeral), which is in agreement with the report by Ikeda et al. (2015, 2016). During the winter, the temperatures towards midday and midnight are comparatively mild compared to the cold winds that come during twilight hours (Claudino-Sales 2019). Towards the later winter months, ungulates often undergo nocturnal hypometabolism (i.e. decrease in heat production) as a response to peripheral cooling that is indicative of energetically challenging conditions (Signer et al. 2011; Turbill et al. 2011). This phenomenon in conjunction with related sun basking behaviors during both sunrise and sunset may be responsible for the low activity levels seen in sika deer during this time. In addition, winter daytime activity patterns could also result from a reduction in energy consumption as suggested by Arnold et al. (2004).

With regard to daily registrations of sika deer with other sympatric species, roe deer showed a high degree of overlap $\left(\Delta_{4}=0.80 ; \mathrm{CI}=0.75-0.88\right)$. The activity of both species was high during twilight periods, but the peaks were more pronounced for sika deer. Although the diet of sika deer in Korea has not been studied in detail, it is likely that they exhibit similar resource demands to roe deer in both diet and habitat use within our survey area. Our study area contained mostly flat land dominated by forbs, graminoids, and herbs. Adhikari et al. (2016) reported forbs and graminoids contributed a relatively higher proportion of roe deer diet in Jeju Island. According to previous studies from Japan (Yokoyama et al. 2000; Takatsuki 2009), sika deer are commonly found in forests (either coniferous or deciduous) dominated by browse, forbs, and graminoids, which form a major part of their diet in all seasons. The presence of a commonly preferred diet causes both deer species to aggregate in similar areas, even if the diet overlap interspecific competition is not always the consequence. Two species can co-exist without detriment to one another, if they have a preferred food that is abundant (Pianka 1974; Obidziński et al. 2013).

The management of invasive sika deer can be best planned with proper understanding of the activity patterns of the species as it exists in South Korea. Although our study was limited by the relatively low number of camera traps and survey sites, these data shed light on the diel and seasonal activity patterns of sika deer.

\section{Conclusion}

This study, conducted in the Muljangori-oreum wetlands of Jeju Island, shows that sika deer were active throughout the day and night, with peaks at dawn and dusk. On a seasonal scale, it showed variation in activity patterns (dawn and dusk in spring-autumn; day and night in winter) that could be linked to changes in temperature and the stresses that come with harsh winter weather conditions. In this study, native roe deer showed a higher incidence of activity overlap with sika deer than any other study species, suggesting that the two ungulates likely share common dietary preferences. This study provides valuable information about the diel and overlapping activity patterns of alien sika deer; these data will prove invaluable for the development of management strategies in future.

\section{Abbreviations}

IAS: Invasive alien species; MOE: Ministry of Education; UNESCO: United Nations Educational, Scientific and Cultural Organization

\section{Acknowledgements}

The research was supported by the 2020 scientific promotion program funded by Jeju National University.

\section{Authors' contributions}

MRB carried out the field study and wrote the manuscript. SHH and HSO participated in the field design and reviewed/edited the manuscript. YHJ performed the analysis and conducted the field study. The author(s) read and approved the final manuscript.

\section{Funding}

The research was funded by Jeju National University.

\section{Availability of data and materials}

The datasets generated and/or analysed during the current study are available from corresponding authors on reasonable request.

\section{Declarations}

Ethics approval and consent to participate

Korean Wildlife Conservation guideline has been followed.

Consent for publication

Not applicable

Competing interests

The authors declare that they have no competing interests. 


\section{Author details}

'Faculty of Science Education, Jeju National University, Jeju 63243, South Korea. ${ }^{2}$ Korean National Park Institute of Biodiversity Conservation, Korean National Park Service, Gurye 57616, South Korea. ${ }^{3}$ Interdisciplinary Graduate Programme in Advance Convergence Technology and Science, Faculty of Science Education, Jeju National University, Jeju 63243, South Korea.

\section{Received: 9 January 2021 Accepted: 26 May 2021}

\section{Published online: 29 June 2021}

\section{References}

Adhikari P, Jeon J, Kim HW, Shin M, Adhikari P, Seo C. Potential impact of climate change on plant invasion in the Republic of Korea. J Ecol Environ. 2019;43(1): 36. https://doi.org/10.1186/s41610-019-0134-3.

Adhikari P, Park SM, Kim TW, Lee JW, Kim GR, Han SH, et al. Seasonal and altitudinal variation in roe deer (Capreolus pygargus tianschanicus) diet on Jeju Island, South Korea. J Asia-Pacific Biodivers. 2016;9(4):422-8. https://doi, org/10.1016/j.japb.2016.09.001.

Arnold W, Ruf T, Reimoser S, Tataruch F, Onderscheka K, Schober F. Nocturnal hypometabolism as an overwintering strategy of red deer (Cervus elaphus). Am J Physiol Regul Integr Comp Physiol. 2004;286(1 55-1):174-81.

Bartos L. Sika deer in continental Europe In: McCullough DR, Kaji K, Takatsuki S (eds) Sika deer. Biology and management of native and introduced populations. Springer, Berlin Heidelberg New York 5. 2009.

Bennie JJ, Duffy JP, Inger R, Gaston KJ. Biogeography of time partitioning in mammals. Proc Natl Acad Sci U S A. 2014;111(38):13727-32. https://doi.org/1 0.1073/pnas.1216063110.

Berger A, Scheibe KM, Brelurut A, Schober F, Streich WJ. Seasonal variation of diurnal and ultradian rhythms in red deer. Biol Rhythm Res. 2002;33(3):23753. https://doi.org/10.1076/brhm.33.3.237.8259.

Bertolino S, di Montezemolo NC, Bassano B. Food-niche relationships within a guild of alpine ungulatesincluding an introduced specie s. J Zool. 2009; 277(1):63-9. https://doi.org/10.1111/j.1469-7998.2008.00512.x.

Biedrzycka A, Solarz W, Okarma H. Hybridization between native and introduced species of deer in Eastern Europe Hybridization between native and introduced species of deer in Eastern Europe. J Mammal. 2012;93(5):1331-41. https://doi.org/10.1644/11-MAMM-A-022.1.

Borkowski J. Flight behaviour and observability in human-disturbed sika deer Flight behaviour and observability in human-disturbed sika deer. Acta Theriol (Warsz). 2001;46(2):195-206. https://doi.org/10.4098/AT.arch.01-21.

Bourgoin G, Garel M, Blanchard P, Dubray D, Maillard D, Gaillard JM. Daily responses of mouflon (Ovis gmelini musimon $\times$ Ovis sp.) activity to summer climatic conditions. Can J Zool. 2011;89(9):765-73. https://doi.org/10.1139/ Z11-046.

Brivio F, Bertolucci C, Tettamanti F, Filli F, Apollonio M, Grignolio S. The weather dictates the rhythms: Alpine chamois activity is well adapted to ecological conditions. Behav Ecol Sociobiol. 2016;70(8):1291-304. https://doi.org/10.1 007/s00265-016-2137-8.

Carpio AJ, Guerrero-casado J, Barasona JA. Hunting as a source of alien species: a European review. Biol Invasions. 2016;19(4):1197-1211.

Centore L, Ugarkovic D, Scaravelli D, Safner T, Panduric K, Sprem N. Locomotor activity pattern of two recently introduced non-native ungulate species in a Mediterranean habitat. Folia Zool. 2018;67(1):17-24.

Claudino-Sales V. Coastal world heritage sites, vol. 28; 2019.

Cooke AS, Farrell L. Impact of muntjac deer ( Muntiacus reevesi ) at Monks Wood National Nature Reserve, Cambridgeshire, eastern England. Forestry. 2001; 74(3):241-250.

Cote SD. Extirpation of a large black bear population by introduced white-tailed deer. Conserv Biol. 2005;19(5):1668-71. https://doi.org/10.1111/j.1523-1739.2 005.00252.x.

Doncaster C, Davey AJ. Book Review: Analysis of variance and covariance: how to choose and construct models for the life sciences, vol. 140. Cambridge: Cambride University Press; 2007. https://doi.org/10.1017/CBO9780511611377.

Ensing EP, Ciuti S, De Wijs FALM, Lentferink DH, Hoedt A, Boyce MS, et al. GPS based daily activity patterns in european red deer and North American elk (Cervus elaphus): Indication for a weak circadian clock in ungulates. PLoS One. 2014;9(9):e106997. https://doi.org/10.1371/journal.pone.0106997.

Feretti F. Interspecific aggression between fallow and roe deer. Ethol Ecol Evol. 2011;23(2):179-86. https://doi.org/10.1080/03949370.2011.554883.
Foster VC, Sarmento P, Sollmann R, Torres N, Jacomo ATA, Negroes N, et al. Jaguar and Puma activity patterns and predator-prey interactions in four Brazilian biomes. Biotropica. 2013;45(3):373-9. https://doi.org/10.1111/btp.12021.

Fraser KW. Comparative rumen morphology of sympatric sika deer (Cervus nippon) and red deer (C. elaphus scoticus) in the Ahimanawa and Kaweka Ranges, central North Island, New Zealand. Oecologia. 1996;105(2):160-6. https://doi.org/10.1007/BF00328541.

Garcia-Llorente M, Martin-Lopez B, Gonzalez JA, Alcorlo P, Montes C. Social perceptions of the impacts and benefits of invasive alien species: implications for management. Biol Bull. 2008;1:2969-83.

Green RA, Bear GD. Seasonal cycles and daily activity patterns of rocky mountain elk. J Wild Manag. 1990;54(2):272. https://doi.org/10.2307/3809041.

Greenberg S. Timelapse User Guide: An image analyser for camera traps. Greenberg Consulting Inc. / University of Calgary, Calgary, Alberta, Canada. 2019:1-127. Version 2.2.2.9.

Igota H, Sakuragi M, Uno H, Kaji K, Kaneko M, Akamatsu R, et al. Seasonal migration patterns of female sika deer in eastern Hokkaido, Japan. Ecol Res. 2004;19(2):169-78. https://doi.org/10.1111/j.1440-1703.2003.00621.x.

Ikeda T, Takahashi H, Igota H, Matsuura Y. Effects of culling intensity on diel and seasonal activity patterns of sika deer (Cervus nippon). Sci Rep. 2019;9:1-8.

Ikeda T, Takahashi H, Yoshida T, Igota H, Matsuura Y, Takeshita K, et al. Seasonal variation of activity pattern in sika deer ( Cervus nippon ) as assessed by camera trap survey. Mammal Study. 2015;40(4):199-205. https://doi.org/10.31 06/041.040.0401.

Ikeda T, Uchida K, Matsuura Y, Takahashi H, Yoshida T, Kaji K, et al. Seasonal and diel activity patterns of eight sympatric mammals in northern Japan revealed by an intensive camera-trap survey. PLoS One. 2016;11(10):e0163602. https:// doi.org/10.1371/journal.pone.0163602.

Jin K. The analytical study for sika deer behaviour pattern and characteristics of their habitats through monitoring the sika deer released at the urban forests in South Korea. Korean J Environ Biol. 2013;31 (4):322-32. https://doi.org/10.11 626/KJEB.2013.31.4.322.

Jo YS, Baccus JT, Koprowski JL. Mammals of Korea: a review of their taxonomy, distribution and conservation status. Zootaxa. 2018;4522(1):1-216. https://doi. org/10.11646/zootaxa.4522.1.1.

Kaji K, Saitoh T, Uno H, Matsuda H, Yamamura K. Adaptive management of sika deer populations in Hokkaido, Japan: theory and practice. Popul Ecol. 2010; 52(3):373-87. https://doi.org/10.1007/s10144-010-0219-4.

Kim WB, Kim YH, Oh JG. Distribution of birds in the Jeju seonheul gotjawal region, a survey site of long-term ecological study. J Korean Nat. 2012;5(2): 115-9. https://doi.org/10.7229/jkn.2012.5.2.115.

Koh HS, Yang BK, Lee BK, Jang KH, In ST, Lee JH, et al. Species identification of the sika deer, in deer farms from Northeastern China, North Korea, and Korea, revealed by the sequencing of mitochondrial DNA cytochrome $b$ gene. Bull Nat Sci. 2010;24:7-11.

Lee M. Discovering wetlands: a guide to ramsar wetlands and wetland protection areas of Korea; 2008.

Liang Y, Kuo H, Giordano AJ, Pei KJ. Seasonal variation in herd composition of the Formosan sika deer (Cervus nippon taiouanus) in a forest-grassland mosaic habitat of southern Taiwan. Glob Ecol Conserv. 2020;24(1):e01283. https://doi.org/10.1016/j.gecco.2020.e01283.

Linkie M, Ridout MS. Assessing tiger-prey interactions in Sumatran rainforests. J Zool. 2011;284(3):224-9. https://doi.org/10.1111/j.1469-7998.2011.00801.x.

Lund U, Claudio A, Hiroyoshi A, Alessando G, Portugues EG, Giunchi D, Irisson JO, Pocernich M, Rotolo F. Circular statistics. R package version 0.4-93. 2017 Available from: https://cran.r-project.org/package=circular.

Massara RL, Paschoal A Maria DO, Bailey LL, Doherty PF Jr, MDF B, Chiarello AG. Effect of humans and pumas on the temporal activity of ocelots in protected areas of Atlantic Forest effect of humans and pumas on the temporal activity of ocelots in protected areas of Atlantic Forest. Mamm Biol. 2018;92:86-93.

Meredith M, Ridout M. Estimates of coefficient of overlapping for animal activity patterns. Available from: R package version 0.3.2. 2018. https://cran.r-project. org/web/packages/overlap/index.html.

MoE. ECOREA, An Environmental Review 2011.

Niedballa J, Sollmann R, Courtiol A, Wilting A. camtrapR: an R package for efficient camera trap data management. Methods Ecol Evol. 2016;7(12):145762. https://doi.org/10.1111/2041-210X.12600.

O'Brien TG, Kinnaird MF, Wibisono HT. Crouching tigers, hidden prey: Sumatran tiger and prey populations in a tropical forest landscape. Anim Conserv. 2003;6(2):131-9. https://doi.org/10.1017/\$1367943003003172. 
Obidziński A, Kiełtyk P, Borkowski J, Bolibok L, Remuszko K. Autumn-winter diet overlap of fallow, red, and roe deer in forest ecosystems, Southern Poland. Cent Eur J Biol. 2013;8(1):8-17.

Oh H, Park S, Adhikari P, Kim Y, Kim T-W, Han S-H. Distribution and status of the alien invasive red-eared slider (Trachemys scripta elegans) in Jeju Island, South Korea. Korean J Environ Biol. 2017;35(1):57-63. https://doi.org/10.1162 6/KJEB.2017.35.1.057.

Pagon N, Grignolio S, Pipia A, Bongi P, Bertolucci C, Apollonio M. Seasonal variation of activity patterns in roe deer in a temperate forested area. Chronobiol Int. 2013;30(6):772-85. https://doi.org/10.3109/07420528.2013. 765887.

Palmer MS, Swanson A, Kosmala M, Arnold T, Packer C. Evaluating relative abundance indices for terrestrial herbivores from large-scale camera trap surveys. Afr J Ecol. 2018;56(4):791-803. https://doi.org/10.1111/aje.12566.

Paul B, Mccullough DR. Factor influencing white-tailed deer activity patterns and habitat use. Wildl Monogr. 1990;(109):3-51.

Pęsa $Ł$, Ciach M. Daytime activity budget of an alpine ungulate (Tatra chamois Rupicapra rupicapra tatrica): influence of herd size, sex, weather and human disturbance. Mammal Res. 2018;63(4):443-53. https://doi.org/10.1007/s13364018-0376-y.

Pianka ER. Niche overlap and diffuse competition. Proc Natl Acad Sci USA. 1974; 71(5):2141-5. https://doi.org/10.1073/pnas.71.5.2141.

Prpic AM, Gancevic P, Safner T, Kavcic K, Jerina K, Nikica S. Activity patterns of aoudad (Ammotragus lervia) in a Mediterranean habitat. J Vertebr Biol. 2020; 69(4):20055.

Putman RJ. Competition and resource partitioning in temperate ungulate assemblies. Vol. 3. Springer Science and Business Media; 1996.

R Development Core Team. R: A Language and Environment for Statistical Computing. Vienna: R Foundation for Statistical Computing; 2015.

Ridout MS, Linkie M. Estimating overlap of daily activity patterns from camera trap data. J Agric Biol Environ Stat. 2009;14(3):322-37. https://doi.org/10.1198/ jabes.2009.08038.

Rowcliffe JM, Kays R, Kranstauber B, Carbone C, Jansen PA. Quantifying levels of animal activity using camera trap data. Methods Ecol Evol. 2014;5(11):1170-9. https://doi.org/10.1111/2041-210X.12278.

Russell M, Woodall CW, Potter KM, Walters BF, Domke GM, Oswalt CM. Interactions between white-tailed deer density and the composition of forest understories in the northern United States. For Ecol Manag. 2017;384:26-33. https://doi.org/10.1016/j.foreco.2016.10.038.

Sidell BP. Moonrise 3.5; 2002. Available from http://moonrise.us/moonrise.html

Signer C, Ruf T, Arnold W. Hypometabolism and basking: The strategies of Alpine ibex to endure harsh over-wintering conditions. Funct Ecol. 2011;25(3):53747. https://doi.org/10.1111/j.1365-2435.2010.01806.x.

Spear D, Chown SL. Non-indigenous ungulates as a threat to biodiversity. J Zool. 2009;279(1):1-17. https://doi.org/10.1111/j.1469-7998.2009.00604.x.

Stache A, Heller E, Hothorn T, Heurich M. Activity patterns of European roe deer (capreolus capreolus) are strongly influenced by individual behaviour. Folia Zool. 2013;62(1):67-75. https://doi.org/10.25225/fozo.v62.11.a10.2013.

Takatsuki S. Geographical variations in food habits of sika deer: the northern grazer vs . the southern browser. In: McCullough DR, Kaji K, Takatsuki S, editors. Sika deer. Biology and management of native and introduced populations. Berlin Heidelberg New York 5: Springer; 2009.

Turbill C, Ruf T, Mang T, Arnold W. Regulation of heart rate and rumen temperature in red deer: Effects of season and food intake. J Exp Biol. 2011; 214(6):963-70. https://doi.org/10.1242/jeb.052282.

Turner DC. An analysis of time-budgeting by roe deer (Capreolus capreo/us) in an agricultural area. Behaviour. 1979;71(3):246-90. https://doi.org/10.1163/1 $56853979 \times 00188$.

Worton BJ. Kernel methods for estimating the utilization distribution in homerange studies. Ecology. 1989;70(1):164-8. https://doi.org/10.2307/1938423.

Yokoyama M, Kaji K, Suzuki M. Food habits of sika deer and nutritional value of sika deer diets in eastern Hokkaido, Japan. Ecol Res. 2000;15(3):345-55. https://doi.org/10.1046/j.1440-1703.2000.00355.x.

\section{Publisher's Note}

Springer Nature remains neutral with regard to jurisdictional claims in published maps and institutional affiliations.

\section{Ready to submit your research? Choose BMC and benefit from}

- fast, convenient online submission

- thorough peer review by experienced researchers in your field

- rapid publication on acceptance

- support for research data, including large and complex data types

- gold Open Access which fosters wider collaboration and increased citations

- maximum visibility for your research: over $100 \mathrm{M}$ website views per year

At BMC, research is always in progress.

Learn more biomedcentral.com/submissions 